\title{
Granuloma annulare
}

\author{
SUSANNAH MC GEORGE,1 SHERNAZ WALTON²
}

\begin{abstract}
Granuloma annulare is a benign, self-limiting condition that occurs in $4 \%$ of patients with diabetes. It is usually asymptomatic; various clinical subtypes have been described, including localised, generalised, subcutaneous and perforating. The aetiology and pathogenesis is unknown, although several theories have been proposed. Numerous therapeutic strategies are documented in the literature, however, while treatment may be requested for cosmetically disfiguring or pruritic lesions, an explanation of the condition is often all that is necessary.

Br J Diabetes 2016;16:58-61
\end{abstract}

Key words: granuloma annulare, diabetes, skin, dermatology

\section{Introduction}

Granuloma annulare (GA) is a benign, often asymptomatic and self-limiting skin condition. ${ }^{1}$ In the second part of this article, we review the aetiology, pathogenesis, clinical features and management of this condition.

\section{Aetiology}

A number of different theories have been suggested to explain the pathogenesis of GA. It is frequently thought to occur as a response to various external stimuli. These include insect ${ }^{2}$ and animal bites, vaccination reactions and trauma. ${ }^{3,4} \mathrm{~A}$ variety of infectious agents have been implicated, including tuberculosis, Borrelia, varicella, EBV, hepatitis B and C and HIV ${ }^{4,5}$ Sun exposure and phototherapy with psoralen combined with ultraviolet $A$ are also reported to precipitate GA.4,6 Reported drug causes of GA included amlodipine, gold, allopurinol, diclofenac, quinidine, intra-nasal calcitonin and anti-tumour necrosis factor (TNF) agents. 6,7 In one study $15 \%$ of patients attributed onset of GA to psychological stress. ${ }^{5}$

It has been suggested that GA is due to a delayed type hypersensitivity reaction, ${ }^{5}$ but other theories have also been pro-

Department of Dermatology, East Sussex Healthcare NHS Trust Department of Dermatology, Hull and East Yorkshire Hospitals NHS Trust and Hull York Medical School, Hull, UK

Address for correspondence: Dr Susannah George Department of Dermatology, Eastbourne District General Hospital, King's Drive, Eastbourne, East Sussex, BN21 2UD, UK

Tel: $+44(0) 1323417400$ ext 3715

E-mail: susannah@susannahgeorge.net

http://dx.doi.org/10.15277/bjdvd.2015.044 posed. These include the possibility that GA results from the expression of TNF $\alpha$ and matrix metalloproteinases by activated macrophages leading to matrix degeneration. Other theories include the possibility that GA occurs as a result of a T helper cell (Th1)-mediated process, elastic fibre degeneration ${ }^{6}$ due to elastase released from polymorphonuclear leucocytes, ${ }^{8}$ or dermal damage occurring as a result of vasculitis. ${ }^{8}$ The metabolic and microangiopathic effects of diabetes have also been proposed as a cause of collagen destruction. ${ }^{8}$

\section{Association with diabetes}

GA occurs more frequently in females. 5,9 The average age of onset varies by clinical subtype. 10,11 Historically, GA has been reported to be associated with diabetes. In a study of 557 patients with GA, Muhlemann and Williams found that 24 (4\%) had diabetes. ${ }^{9}$ Eighteen had type 1 diabetes and six had type 2 diabetes; 16 of the 18 patients with type 1 diabetes had diabetes at presentation. The number of cases expected in an age-matched population was 0.9, confirming an association with type 1 diabetes. Studer et al found that $12 \%(10 / 84)$ patients with GA had diabetes. ${ }^{5}$ These patients were significantly more likely to experience recurrent disease and $6 / 10$ reported exacerbation of their skin with poor glycaemic control. A subsequent case control study found no association between type 2 diabetes and GA. ${ }^{12}$ However, the control group used were patients with psoriasis, a condition now known to be associated with a number of comorbidities, including diabetes. Limitations to these studies include their retrospective nature and absence of histological confirmation in many cases.

Despite the association of GA and necrobiosis lipoidica (NL) with diabetes, they have only very rarely been reported to occur sequentially in the same patient. ${ }^{13,14}$ Possible reasons for the apparent different rates of association with diabetes could be explained by differences in the pathogenesis of these conditions.

Associations with clinical conditions other than diabetes have been reported. ${ }^{6}$ There have been numerous descriptions of GA occurring in patients with malignancies, but larger studies revealed conflicting results. Several of the patients in the study by Studer et al had malignant disease, but incidence was not different to the general population and onset of GA not temporally related. 6 Hawryluk et al reviewed the evidence for the association of GA and malignant disease: although they concluded there was no causative relationship between malignancy and GA, atypical presentations or GA occurring in an elderly patient should prompt age-appropriate screening for malignancy and evaluation of immune state. ${ }^{15} \mathrm{GA}$ has also been reported in association with thyroid abnormalities and dyslipidaemia. ${ }^{16}$ 
Figure 1. Localised granuloma annulare on the dorsum of the hand

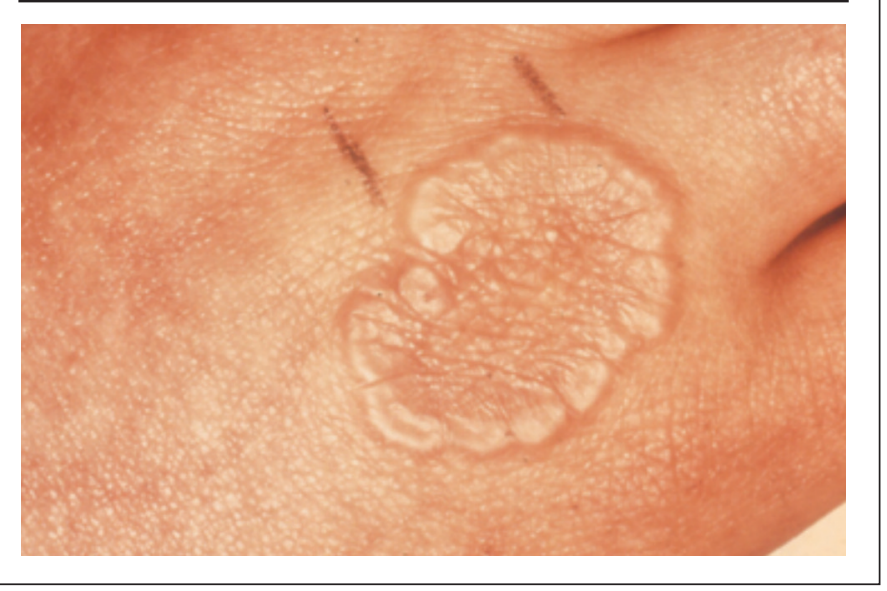

\section{Clinical features}

GA can affect any body site, but especially the hands, arms, feet, lower legs and trunk. ${ }^{5}$ About $60 \%$ have involvement of their upper limbs alone. ${ }^{17}$ There are a number of different clinical subtypes, including localised, generalised/disseminated, subcutaneous or perforating GA.

Localised GA is the most common form, occurring in 75-93\% of patients 5,9 and typically appears as a ring of small flesh-coloured or erythematous papules on the extremities in children and young adults (Figures 1 and 2). Fifty percent have a single lesion. ${ }^{17}$ The initial lesion is an asymptomatic fleshcoloured papule that involutes centrally to form an enlarging annular lesion up to $5 \mathrm{~cm}$ in diameter. The lesions may resolve spontaneously or persist for years. ${ }^{11,18}$

Generalised GA most commonly affects middle-aged or elderly patients ( $80 \%$ of cases), but $20 \%$ of patients present before the age of 10 . It accounts for about 15\% (2.8-25\%) of cases of GA.5,6,9,10 Clinically, generalised GA appears as multiple annular plaques or multiple symmetrically distributed papules on the arms, neck, upper trunk and less often the legs (Figures 3 and 4). 1,18 Subcutaneous GA occurs most commonly in children under 5 years of age and appears as asymptomatic subcutaneous nodules on the hands, scalp, buttocks, shins and periorbital skin. ${ }^{19}$ The condition is self-limiting and does not appear to have any systemic associations. ${ }^{19,20}$ Perforating GA manifests as 1-4mm umbilicated papules on the extremities and most frequently affects children and young adults and may be localised or generalised. ${ }^{18,19}$

\section{Diagnosis}

Diagnosis of GA is often clinical, but biopsies may be performed in cases of diagnostic uncertainty. Diagnosis should prompt investigations for diabetes and other related conditions such as dyslipidaemia.

\section{Histopathology}

The histology of GA is characterised by necrobiotic granulomas:
Figure 2. Localised granuloma annulare on the dorsum of the hand (reproduced with permission of Dr Niels Veien, Danderm)

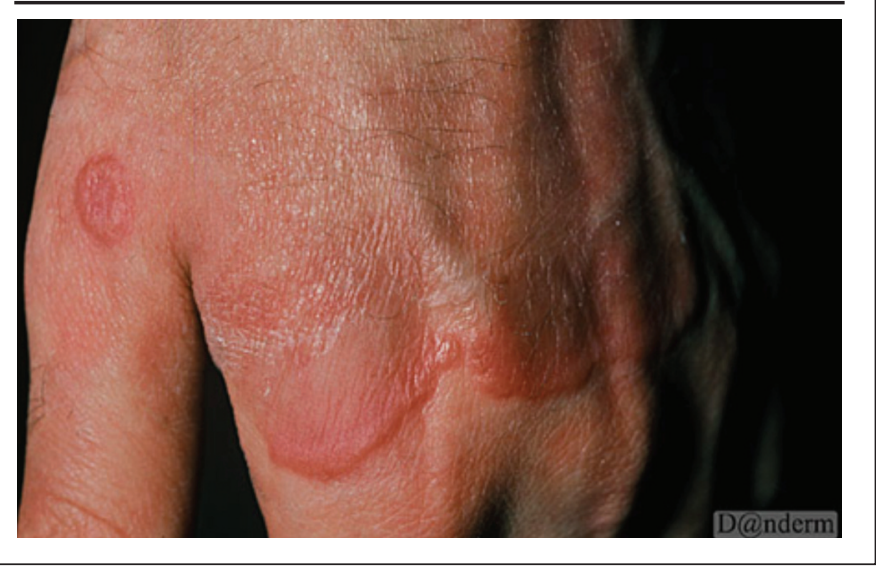

foci of mucin-containing necrobiosis, surrounded by histiocytes and lymphocytes. ${ }^{4}$ The histiocytes are often palisaded. There is fragmentation of collagen bundles and elastic fibres are absent or reduced. Four different histological patterns have been described: interstitial (diffuse macrophage infiltration between degenerated collagen fibres), palisading granulomatous (palisading macrophage infiltration surrounding degenerated collagen fibres in the superficial and reticular dermis), a nodular pattern resembling sarcoidosis and a mixed pattern. 6,8 Histological evaluation of perforating GA reveals necrobiotic material being expelled through the epidermis.4,6 Lesions of subcutaneous GA resemble rheumatoid nodules, both clinically and histologically, and often contain large areas of necrobiosis. $^{4}$

The histological appearance of GA may be similar to NL. Histological features found in both conditions include leucocytoclasia, in early lesions, necrobiosis with a lymphohistiocytic infiltrate and epithelioid cells. ${ }^{14}$

\section{Treatment}

As a benign and frequently self-limiting condition, with $50 \%$ of cases of localised disease resolving in 2 years and $80 \%$ clearing after 9 years, ${ }^{17}$ the only treatment necessary may be to provide a diagnosis and an explanation of the condition. However, in some patients lesions are pruritic or treatment may be requested for cosmetic reasons. More than half of patients experience recurrent disease. $^{5}$

Numerous treatments have been described in case reports and series, but larger studies and high quality randomised controlled trials are lacking. Topical or intralesional corticosteroids are the most frequently used treatments for localised GA, but use of topical calcineurin inhibitors has also been reported.21 Other treatments described for localised disease include oral isotretinoin, cryosurgery, low-dose recombinant interferongamma, photodynamic therapy, topical psoralen combined with ultraviolet A (PUVA) or laser ( $\mathrm{CO}_{2}$-pulsed-dye, excimer, ND:YAG). 4,6 There is anecdotal evidence of patch-type GA lesions resolving after biopsy. 22 
Figure 3. Generalised or disseminated granuloma annulare with widespread, small brownish plaques and papules

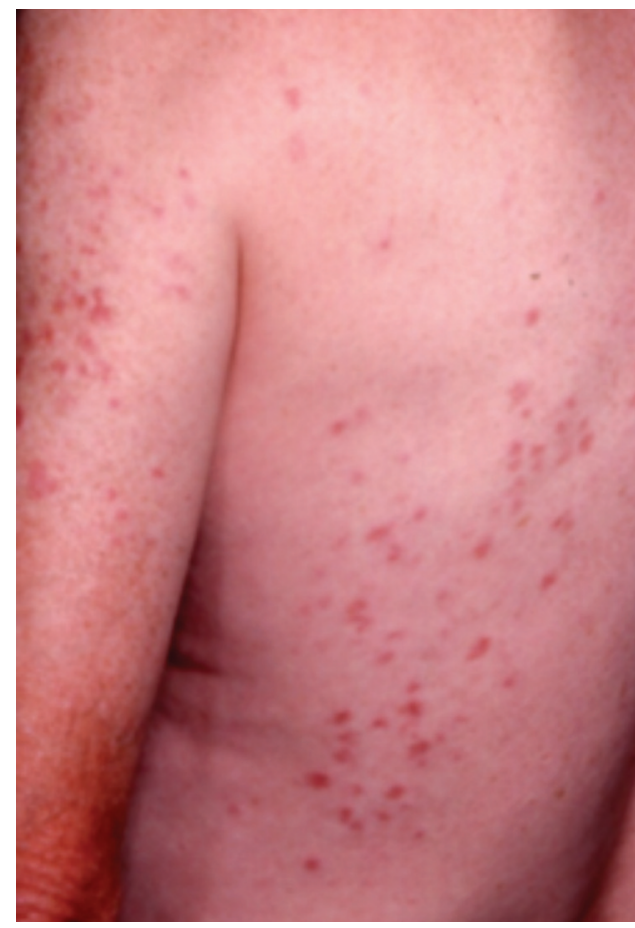

Figure 4. Generalised granuloma annulare showing several small well-demarcated lesions with a shiny papular border

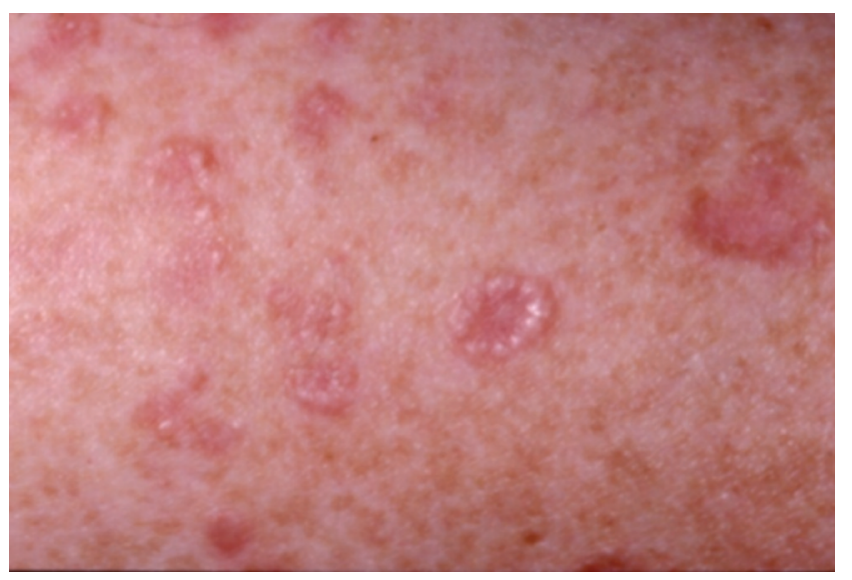

A variety of systemic therapies have been described including oral corticosteroids, antibiotics, antimalarials, fumaric acid esters, ${ }^{23}$ isotretinoin, biologic (anti-TNF) agents, ciclosporin, dapsone, niacinamide, vitamin E, chlorambucil, pentoxifylline, PUVA $^{24}$ and narrow-band ultraviolet B phototherapy. 4,6,19 Resolution of GA was reported in a case of a Japanese female with hypertriglyceridaemia with a strict lipid-lowering diet. ${ }^{25}$

\section{Key messages}

- Granuloma annulare is a benign, often asymptomatic and self-limiting condition

- It is found in $4 \%$ of patients with diabetes

- Clinical subtypes include localised, generalised, subcutaneous and perforating granuloma annulare

- Numerous therapeutic strategies have been described, however an explanation of the condition may be all that is required

While several treatments have been reported in the medical literature, in clinical practice it is difficult to justify exposing patients to treatments for which there is little evidence for what it very likely to be a self-limiting condition.

\section{Conflict of interest None \\ Funding None}

\section{References}

1. Jelinek JE. Cutaneous manifestations of diabetes mellitus. Int J Dermatol 1994;33:605-17. http://dx.doi.org/10.1111/j.1365-4362.1994.tb02915.x

2. Sonthalia S, Arora R, Sarkar R, Khopkar U. F1000Res 2014;3:32. http://dx.doi.org/10.12688/f1000research.3-32.v1

3. Hu SW, Kaplan J, Patel RR, Kamino H. Trauma-related papular granuloma annular. Dermatol Online J 2013;19:20719.

4. Burns DA. Necrobiotic Disorders. In: Burns DA, Breathnach SM, Cox NH, Griffiths CEM (eds). Rook's Textbook of Dermatology, 8th edition, 2010, Oxford, Blackwell Publishing Ltd. 60.1-60.16.

http://dx.doi.org/10.1002/9781444317633.ch60

5. Studer EM, Calza AM, Saurat JH. Precipitating factors and associated diseases in 84 patients with granuloma annulare: a retrospective study. Dermatology 1996;193:364-8. http://dx.doi.org/10.1159/000246297

6. Thornsberry LA, English JC 3rd. Etiology, diagnosis, and therapeutic management of granuloma annulare: an update. Am J Clin Dermatol 2013;14:279-90. http://dx. doi.org/10.1007/s40257-013-0029-5

7. Singh SK, Manchanda K, Bhayana AA, Verma A. Allopurinol induced granuloma annulare in a patient of lepromatous leprosy. J Pharmacol Pharmacother 2013;4:152-4. http://dx.doi.org/10.4103/0976-500X.110915

8. Güneş P, Göktay F, Mansur AT, Köker F, Erfan G. Collagen-elastic tissue changes and vascular involvement in granuloma annulare: a review of 35 cases. J Cutan Pathol 2009;36:838-44. http://dx.doi.org/10.1111/j.1600-0560.2008.01169.x

9. Muhlemann MF, Williams DR. Localized granuloma annulare is associated with insulin-dependent diabetes mellitus. Br J Dermatol 1984;111:325-9. http://dx.doi.org/10.1111/j.1365-2133.1984.tb04730.x

10. Pătraşcu V, Giurcă C, Ciurea RN, Georgescu CV. Rom J Morphol Embryol 2013;54:327-31.

11. Muhlbauer JE. Granuloma annulare. J Am Acad Dermato/ 1980;3:21730. http://dx. doi.org/10.1016/S0190-9622(80)80181-2

12. Nebesio CL, Lewis $C$, Chuang TY. Lack of an association between granuloma annulare and type 2 diabetes mellitus. $\mathrm{Br} J$ Dermatol 2002;146:122-4. http://dx.doi.org/10.1046/j.0007-0963.2001.04527.x

13. Souza FH, Ribeiro CF, Pereira MA, Mesquita L, Fabrício L. Simultaneous occurrence of ulcerated necrobiosis lipoidica and granuloma annulare in a patient: case report. An Bras Dermatol 2011;86:1007-10. http://dx.doi.org/10.1590/S0365-05962011000500023

14. Rupley KA, Riahi RR, O'Boyle Hooper D. Granuloma annulare and necrobiosis lipoidica with sequential occurrence in a patient: report and review of literature. Dermatol Pract Concept 2015;5:3. http://dx.doi.org/10.5826/dpc.0501a03 
15. Hawryluk EB, Izikson L, English JC 3rd. Non-infectious granulomatous diseases of the skin and their associated systemic diseases: an evidencebased update to important clinical questions. Am J Clin Dermatol 2010; 11:171-81. http://dx.doi.org/10.2165/11530080-000000000-00000

16. Wu W, Robinson-Bostom L, Kokkotou E, Jung HY, Kroumpouzos G. Dyslipidemia in granuloma annulare: a case-control study. Arch Dermatol 2012;148:1131-6. http://dx.doi.org/10.1001/archdermatol.2012.1381

17. Wells RS, Smith MA. The natural history of granuloma annulare. $\mathrm{Br} J$ Dermatol 1963;75:199-205. http://dx.doi.org/10.1111/j.1365-2133. 1963.tb13549.x

18. Ahmed I, Goldstein B. Diabetes mellitus. Clin Dermatol 2006:24:23746. http://dx.doi.org/10.1016/j.clindermatol.2006.04.009

19. Cyr PR. Diagnosis and management of granuloma annulare. Am Fam Physician 2006;74:1729-34.

20. Sabuncuoğlu H, Oge K, Söylemezoğlu F, Sağlam A. Subcutaneous granuloma annulare of the scalp in childhood: a case report and review of the literature. Turk Neurosurg 2007;17:19-22.

21. Grieco T, Cantisani C, Faina P, et al. Tacrolimus $0.1 \%$ and granuloma annulare: description of three cases. J Eur Acad Dermatol Venereol 2009;12:1445-6. http://dx.doi.org/10.1111/j.1468-3083.2009.03217.x

22. Levin NA, Patterson JW, Yao LL, Wilson BB. Resolution of patch-type granuloma annulare lesions after biopsy. I Am Acad Dermatol 2002;46:426-9. http://dx.doi.org/10.1067/mjd.2002.118344

23. Wollina U. Granuloma annulare disseminatum responding to fumaric acid esters. Dermatol Online J 2008:14:12.

24. Schmutz JL. PUVA therapy of granuloma annulare. Clin Exp Dermatol 2000;25:451. http://dx.doi.org/10.1046/j.1365-2230.2000.00685.x

25. Watanabe S, Tanaka M, Kobayashi K, et al. Remission of generalized erythematous granuloma annulare after improvement of hyperlipidemia and review of the Japanese literature. Dermatol Pract Concept 2014:4:97-100. http://dx.doi.org/10.5826/dpc.0401a17

\section{ACCU-CHEK}

\section{Sometimes}

there are only good choices.

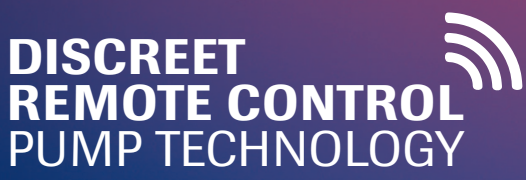

DISCREET PUMP TECHNOLOGY 